\title{
Farklı Yıllarda Hasat Edilen Kenevir Tohumlarının Bazı Fiziksel Özelliklerinin Belirlenmesi
}

\author{
Zeynep Dumanoğlư ${ }^{*}$, Sıdıka Ekren $^{2}$, Gülsüm Öztürk ${ }^{3}$, Adem Gökçöl ${ }^{4}$, Emre İlker $^{5}$, Hakan Geren ${ }^{6}$ \\ ${ }^{1}$ Bingöl Üniversitesi Ziraat Fakültesi Biyosistem Mühendisliği Bölümü, 12000, Bingöl, Türkiye (ORCID: 0000-0002-7889-9015), zdumanoglu@bingol.edu.tr \\ ${ }^{2}$ Ege Üniversitesi Ziraat Fakültesi Tarla Bitkileri Bölümü, 35100, İzmir, Türkiye (ORCID: 0000-0002-6812-9586), sidika.ekren@ ege.edu.tr \\ ${ }^{3}$ Ege Üniversitesi Ziraat Fakültesi Tarla Bitkileri Bölümü, 35100, İzmir,Türkiye (ORCID: 0000-0002-8701-790X), gulsun.ozturk@ ege.edu.tr \\ ${ }^{4}$ Ege Üniversitesi Ziraat Fakültesi Tohum Teknolojisi Uygulama ve Araştırma Merkezi, 35100, İzmir, Türkiye (ORCID: 0000-0002-3866-5898) \\ adem.gokcol@ege.edu.tr \\ ${ }^{5}$ Ege Üniversitesi Ziraat Fakültesi Tarla Bitkileri Bölümü, 35100, İzmir, Türkiye (ORCID: 0000-0002-4870-3907), emre.ilker@ege.edu.tr \\ ${ }^{6}$ Ege Üniversitesi Ziraat Fakültesi Tarla Bitkileri Bölümü, 35100, İzmir, Türkiye (Orcid no:0000-0003-0426-1120), hakan.geren@ege.edu.tr
}

(İlk Geliş Tarihi 25 Mart 2021 ve Kabul Tarihi 17 Haziran 2021)

(DOI: $10.31590 /$ ejosat.902273)

ATIF/REFERENCE: Dumanoğlu, Z., Ekren, S., Öztürk, G., Gökçöl, A., İlker, E. \& Geren, H. (2021). Farklı Y1llarda Hasat Edilen Kenevir Tohumlarının Bazı Fiziksel Özelliklerinin Belirlenmesi. Avrupa Bilim ve Teknoloji Dergisi, (27), 17-21.

$\ddot{O} \mathbf{z}$

Dünyada olduğu gibi Türkiye'de de endüstriyel amaçlarla üretilen kenevir (Cannabis sativa L.) bitkisi, pek çok sektör tarafından değerlendirilmektedir. Bu çalışma, 2021 yılında Ege Üniversitesi ve Bingöl Üniversitesi laboratuvarlarında gerçekleştirilmiştir. Farklı yıllarda hasat edilen Narlı popülasyonuna ait kenevir tohumlarının bazı fiziksel özellikleri (şekil-boyut, yüzey alan, ortalama aritmetik çap-geometrik çap, küresellik, bin dane ağırlığı) belirlenmiştir. Elde edilen sonuçlara göre, bu popülasyonun Ege Bölgesi iklim, çevre ve toprak özelliklerine uyum sağladığı; ilk yıla göre ikinci yıldan elde edilen verilerin daha yüksek olduğu saptanmıştır. Belirlenen bu sonuçların ileride yapılacak olan ıslah ve mekanizasyon çalışmalarına alt yapı sağlaması amaçlanmıştır.

Anahtar Kelimeler: Kenevir, Cannabis sativa L., Tohum özellikleri, Tohum boyutları

\section{Determination of Some Physical Properties of Hemp Seeds Harvested in Different Years}

\begin{abstract}
The hemp (Cannabis sativa) for industrial purposes produced in the world of also in Turkey, are considered by many sectors. This study was carried out in 2021 in the laboratories of Ege University and Bingol University. Some physical properties (shape-size, surface area, average arithmetic diameter-geometric diameter, sphericity, thousand grain weight) of hemp seeds were determined which belonging to the Narl population harvested in different years. According to the results, this population has adapted to the climate, environment and soil characteristics of the Aegean Region; It was determined that the data obtained from the second year were higher compared to the first year. These results are intended to provide a substructure for future improvement and mechanization studies.
\end{abstract}

Keywords: Hemp, Cannabis sativa L., Seed characteristics, Seed sizes

\footnotetext{
*Sorumlu Yazar: zdumanoglu @ bingol.edu.tr
} 


\section{Giriş}

Kenevir (Cannabis sativa L.), Cannabaceae familyasına ait tek yıllık, diploid yapıya sahip bir endüstri bitkisidir. Bu familya kesin olmamakla birlikte dünyada 2 cins ve 4 tür ile temsil edilmekte olup üç türü (C. indica, $C$. ruderalis ve $C$. sativa) yaygın olarak bulunmaktadır (Gönen, 2009; Göre \& Kurt, 2021). Ancak kenevir, ilk olarak Carlous Linnaeus tarafindan 1753 yılında Cannabis sativa L. olarak adlandırılmış; 1785'te biyolog Jean-Baptiste Lamarck Hindistan kökenli olan ve morfolojik olarak farklar bulunan Cannabis indica türünü tanımlarken; 1924 yılında Janischevsky bulunan bu iki türden farklı özelliklere sahip olan Cannabis rudelis'i tanımlamıştır (Anderson, 1980; Gönen, 2009).

Kendir, çedene gibi faklı isimlerle de anılan kenevir, ekvatordan kutuplara kadar çok geniş bir alan içerisinde yetişebilmektedir (Vavilov, 2009). İnsanlık tarihinde ilk kültüre alınan bitkilerden biri olarak belirtilen kenevir (Yıldırım \& Koca Çalışkan, 2020), Avrasya ve Afrika'da farklı şekillerde faydalanılmış (bitkisel kaynak, ilaç hammaddesi gibi), 16.yy.'dan 18.yy.'a kadar keten ile birlikte Rusya, Avrupa ve Kuzey Amerika'da lif bitkisi (iplik, kumaş, sicim, halat vb.) olarak kullanılmış (Pounds, 2010) ancak üretimi yasal sınırlamalar ile belirlenmeye başlandıktan sonra tekstil sanayisinde kullanımından kağıt üretiminde hammadde olarak değerlendirilmeye başlanmıştır. Bu bitki ayrıca inşaat, uzay sanayisi, otomotiv sanayisi, kozmetik, gıda, plastik üretimine kadar pek çok sektör tarafından da değerlendirilmektedir (Schultes et al., 1974; Mathieu, 1980; Aytaç ve ark., 2017; Göre\& Kurt, 2021). Bunların yanında, tohumları kuşyemi ya da kümes hayvanları ile balıkların beslenmesinde ve altlık ya da pelet olarak kullanımı, sabun ve deterjan yapımı ile cila, boya gibi ürünlerin de üretiminde hammadde olarak kullanıldığını eklemek gerekmektedir (Oomah et al., 2002; Gönen, 2009; Aydemir, 2017; Gün, 2019; Başer \& Bozoğlu, 2020; Yıldırım \& Koca Çalışkan, 2020).

Dünyada tohumluk kenevir yetiştiriciliği yıllara bağlı olarak artış göstermiş ve tohumluk kenevir, 2018 yılında yaklaşık 32 bin hektarlık alanda 143 bin tona; tohum dışı olarak ise yaklaşık 41.600 bin hektarda 60.657 tona ulaşan bir üretim kapasitesine ulaşmıştır (FAO, 2019). Tohumluk üretiminin yaklaşık \%99 ile ekili alanların yaklaşık \%95'i Fransa, Çin, Rusya, Şili, Macaristan ve Ukrayna tarafından karşılanmaktadır. Türkiye'de ise, 29.06.2016 tarihli Resmi Gazetede yayınlanan yönetmeliğe göre, 19 ilde (Amasya, Antalya, Bartın, Burdur, Çorum, İzmir, Karabük, Kastamonu, Kayseri, Kütahya, Malatya, Ordu, Rize, Samsun, Sinop, Tokat, Uşak, Yozgat ve Zonguldak) üretim kontrollü olarak gerçekleştirilmektedir. Ayrıca, Samsun Ondokuz Mayıs Üniversitesi ile Yozgat Bozok Üniversitelerinin bünyelerinde olmak üzere iki adet "Kenevir Araştırmaları Enstitüsü” kurulmuştur (Göre\& Kurt, 2021). 2019 y1lında tohumluk kullanım amacına yönelik olarak kenevir üretimi yaklaşık 536 dekar ve 20 ton üretime; tohumluk dişına yönelik kullanım için ise 141 dekara ve 18 tona ulaşılmıştır (TÜIKK, 2020). Ayrıca 2019 yılında gerçekleştirilen “Türkiye'de Endüstriyel Kenevir Yetiştiriciliği Raporu ve Eylem Planı”na göre; kısa vade içerisinde kenevir tohumlarında yerli popülasyonların arttırılması ve bunların tescil edilmesi, tohum çoğaltma işlemlerinin gerçekleştirilmesi ile sertifikalı tohum kullanımına geçilerek kenevire dayalı sanayi ve mekanizasyon sistemlerinin geliştirilmesi, öncelikli yatırım alanlarının belirlenmesi şeklinde kararlar alınmıştır (Başer \& Bozoğlu, 2020). Günümüze kadar yerli popülasyonların geliştirilmesine yönelik yapılan çalışmalar hız kazanmış, mevcut çeşitler, seleksiyon, melezleme, hibrit 1slahı ve markör destekli seleksiyon gibi geleneksel yöntemlerden de faydalanılmaktadır (Yaman, 2020).

Kenevir, 1.5-2 m'ye kadar inebilen kazık kök yapısına sahiptir. Ağaç ya da çalı şeklilerinde olabildiği gibi, tek bir daldan da oluşabilmektedir. İki evcikli (dişi ve erkek ayrı olan) yapıya sahip olduğundan bitkinin genel formu da buna bağlı olarak değişiklik (sap kalınlıkları ve uzunlukları) gösterebilmektedir. Birleşik yaprak yapısına sahip olan bu bitkide bir yaprakta 3-11 adet yaprakçık (1-2 cm genişliğinde, 5$12 \mathrm{~cm}$ uzunluğunda) bulunabilmektedir. Tek sayıda olan bu yaprakçıklar mızrak ya da mekik şeklinde yeşil ve kenar kısımları dişilidir. Bitki boyu yetiştirilme şartlarına ve çeşit özelliklerine bağlı olarak yaklaşık $50-300 \mathrm{~cm}$ arasında değişmektedir (Göre \& Kurt, 2021).

Kenevir bitkisi, havadar, organik maddece zengin, 6-7.5 pH değerine sahip olan toprakları tercih etmektedir. Kısa gün bitkisi olmas1 nedeniyle, günlerin 12 saatten az olduğu zaman aralığında çiçeklenmektedir. Bu durum göz önüne alınarak erken ekiminin yapılması ile vejetatif büyüme dönemi uzatılarak bitki daha dayanıklı ve güçlü yapıya sahip olmaktadır. Tohumluk üretimi için $30-40 \mathrm{~cm}$, lif üretimi içinse $20-25 \mathrm{~cm}$ sıra aralığında ekim yapılmaktadır (İncekara, 1979; Göre \& Kurt, 2021). Buğday ekimi içinde kullanılan pnömatik ekim makinaları ile lif üretimi için 160 bitki $/ \mathrm{m}^{2}$, tohumluk üretimi için $120 \mathrm{bitki} / \mathrm{m}^{2}$ olacak şekilde lif üretimi için 3.5-4 kg/da, tohum üretimi içinse 2.5-3 kg/da tohum kullanılarak ekim işlemi gerçekleştirilebilmektedir (Gizlenci ve ark., 2019; İbiş, 2020). Yıllık yağış miktarı yeterli olan bölgelerde (yaklaşık $700 \mathrm{~mm}$ ) sulama ihtiyacı olmazken, kurak bölgelerde iyi bir verim elde edebilmek için gelişme periyodu boyunca 2-4 defa sulamanın yapılması önerilmektedir (Garcia-Tejero et al., 2014).

Kenevir tohumlarında yaklaşık \%30-35 oranında yă bulunmaktadır (İncekara, 1979; Er \& Y1ldız, 2014; Gizlenci ve ark., 2019). Ayrıca \%20-25 oranında protein, \%20-35 oranında karbonhidrat, \%10-15 oranında lif, fitokannabinoitler ve terpenoitlerce çok zengin vitamin ve mineralleri (E vitamini, Thiamine (B1), Riboflavin (B2), Fosfor, Potasyum, Demir, Magnezyum, Çinko, Bakır) bünyesinde bulundurmaktadır (Yıldırım \& Koca Çalışkan, 2020; Göre \& Kurt, 2021). Kenevir bitkisinin, tohumlarının yanında kök, çiçek, yaprakları, sap ve gövdesi de değerlendirilmektedir. Özellikle ilaç üretim sanayisinin ilgi odağında olan kenevir, yapılan araştırmalara göre; antienflamatuvar, antipiretik, analjezik etkilerinin ve antioksidan aktivitelere neden olduğu belirlenmiştir (Aswar et al., 2010; Antonisamy et al., 2015).

$\mathrm{Bu}$ çalışmada, kenevir (Cannabis sativa $\mathrm{L}$.) tohumlarına ait bazı fiziksel özellikleri belirlenmiştir. Bitkisel üretimde ekimden hasada ve sonrasında ürün işleme basamaklarında dahi tohumun özelliklerinden faydalanılmaktadır. Başarılı bir bitkisel üretim için kaliteli ve sertifikalı tohumluk kullanımı gereklidir. Bu tohumlukların yetiştirilmesinde ve sorasında sınıflandırılarak paketlenmektedir. Boyutlarına göre ayrılan tohumluklarında üreticiye ulaştırılmasında ticari firmalar farklı fiyat politikaları uygulayabilmektedir. Çünkü üretici almış olduğu tohumlukların miktarına göre dekara ya da hektara ne kadar tohum atacağını ve de bunu hangi tür bir ekim makinesi ile gerçekleştireceğini üretim dönemi öncesinde belirlemektedir. $\mathrm{Bu}$ nedenle, her bir bitki türünü temsil eden tohumların özellikleri ayrıca önem taşımaktadır. Bunların yanında yapılan ve yapılacak olan ıslah çalışmalarında tohum özellikleri göz önüne alınarak üreticilerin en yüksek verimi elde edebilecekleri, biyotik ve abiyotik şartlara 
dayanımları yüksek çeşitlerin geliştirilmesine dair araştırmalar yönlendirilmekte ve gerekli yatırımlar yapılmaktadır.

\section{Materyal ve Metot}

Bu çalışma, 2021 yılında Ege Üniversitesi Ziraat Fakültesi Tarla bitkileri Bölümü deneme alanı, Ege Üniversitesi Tohum Teknolojisi Uygulama ve Araştırma Merkezi ve Ege Üniversitesi Ziraat Fakültesi Tarım Makinaları ve Teknolojileri Mühendisliği ile Bingöl Üniversitesi Ziraat Fakültesi Biyosistem Mühendisliği bölümlerine ait laboratuvarlarda yürütülmüştür. $\mathrm{Bu}$ çalışmada incelenen Narlı popülasyonuna ait kenevir (Cannabis sativa L.) tohumu Samsun Ondokuz Mayıs Üniversitesi Ziraat Fakültesi Öğretim Üyelerinden Sayın Prof. Dr. Selim AYTAÇ’dan temin edilmiştir. Daha sonra Ege Üniversitesi deneme parsellerinde (enlem:38 $27^{\prime} \mathrm{N}$; boylam: $27^{\circ} 13^{\prime} \mathrm{E}$, rakım:29m) ekim işlemleri Mart ayı içerisinde gerçekleştirilmiştir. Tohumlar ilk y1l Ekim 2019'da, ikinci y1l Eylül 2020 tarihlerinde hasat edilmiş ve tohumların bu dönem içerisinde yapılan çimlenme testlerinde \%98 ve \%99 çimlenme yeteneğine sahip olduğu belirlenmiştir. $\mathrm{Bu}$ işlemlerin ardından tohumlar kontrollü şartlar altında (yaklaşık $24{ }^{\circ} \mathrm{C}$, nemsiz-kuru, karanlık ortamda cam kavanozlar içerisinde) depolanmıştır.

Tohumlar tesadüf parselleri deneme desenine göre rastgele olacak şekilde örneklenmiş ve bu tohumlara ait bazı fiziksel (şekil-boyut, yüzey alan, ortalama aritmetik-geometrik çap, küresellik ve bin dane ağırlığı) özellikleri belirlenerek, elde edilen değerler temel istatistik parametrelere (minimumortalama-maksimum-standart sapma) göre değerlendirilmiştir.

\subsection{Kenevir tohumlarına ait bazı fiziksel özellikler}

Her tohumun kendisine ait bazı temel özellikleri (uzunluk $(\mathrm{mm})$, genişlik $(\mathrm{mm})$ ve kalınlık $(\mathrm{mm})$ bulunmaktadır. Bitkilerin yetiştirildiği yer başta olmak üzere iklim farklılıkları, toprak özelliklerine ( $\mathrm{pH}$, tuzluluk, kuraklık vb.) ve genotip farklılıklara bağlı olarak tohumların özellikleri de değişim göstermektedir (Dumanoğlu ve ark., 2021). Yapılan araştırmalara (Yağcıŏ̆lu, 2015) bağlı olarak belirlenen temel parametrelere göre tohumların geometrik (uzun-orta-kısa) ve şekil (yuvarlak-ovaluzun) özellikleri sinıflandırılmaktadır (Tablo 1). Ayrıca belirlenen bu temel özelliklerden faydalanılarak tohumlara ait ortalama aritmetik ve geometrik çap ( $\mathrm{mm})$, küresellik gibi diğer verilerde aşağıda belirtilen eşitlikler yardımı ile belirlenebilmektedir (Alayunt, 2000; Kara, 2012; Mohsenin,
1970). Tüm bu değerler kullanılarak, tohumların en az kayıpla tohum yatağına bırakılmaları sağlanmaktadır. Uygun ekici düzen ve ekim makinasının seçilmesi ile başarılı bir ekim işlemi gerçekleştirilebilmekte ayrıca ürün işleme basamağında, tohumların sınıflandırılarak ayrılması ve paketleme işlemleri tamamlanması sağlanmaktadır.

$\mathrm{Bu}$ çalışmada; iki ayrı yıldan ayrı ayrı rastgele olacak şekilde örneklenen kenevir tohumlarının (Cannabis sativa L.) içerisinden 100 'er adet tohum seçilmiş ve kendine ait yazılımı (Image Focus 4.0 v2.4) olan stereo mikroskop (Nexius Zoom) ile tohumlara ait temel özellikler belirlenmiştir (Dumanoğlu \& Çakmak, 2019; Dumanoğlu \& Geren, 2020). Ayrıca her yıla ait kenevir tohumlarının 1000 dane sayımları üçer tekrarlı olacak şekilde yapılmış ve Radwag AS 220.R2 analitik terazi (0.0001 g hassasiyetine) ile tartım işlemleri tamamlanmıştır (ISTA, 2007; Dumanoğlu \& Mokhtarzadeh, 2020).

Tablo1. Tohumların geometrik ve şekil özelliklerine göre sinıflandırılması

\begin{tabular}{c|c|c|c}
\hline $\begin{array}{c}\text { Geometrik } \\
\text { özelliklerine } \\
\text { göre tohumlar }\end{array}$ & $\begin{array}{c}\text { Tane } \\
\text { genişliği/Tane } \\
\text { uzunluğu } \\
(\mathrm{b} / \mathrm{a})(\mathrm{mm})\end{array}$ & $\begin{array}{c}\text { Şekil } \\
\text { özelliklerine } \\
\text { göre } \\
\text { tohumlar }\end{array}$ & $\begin{array}{c}\text { Uzunluk }(\mathrm{a}), \\
\text { Genişlik }(\mathrm{b}), \\
\text { Kalınlık }(\mathrm{c}) \\
(\mathrm{mm})\end{array}$ \\
\hline Uzun & 0.6 & Yuvarlak & $\mathrm{a} \approx \mathrm{b} \approx \mathrm{c}$ \\
Orta & $0.6-0.7$ & Oval & $\mathrm{a} / 3<\mathrm{b} \approx \mathrm{c}$ \\
Kisa & $>0.7$ & Uzun & $\mathrm{c}<\mathrm{b}<\mathrm{a} / 3$ \\
\hline
\end{tabular}

Ortalama Aritmetik Cap:

$D:(L+W) / 2$

D: Tohuma ait ortalama aritmetik çap $(\mathrm{mm})$

L: Tohuma ait uzunluk değeri (mm)

W: Tohuma ait genişlik değeri (mm)

Ortalama Geometrik Çap:

Do: $\left(L * D^{\wedge} 2\right)^{1} / 3$

$\mathrm{D}_{0}$ : Tohuma ait ortalama geometrik çap $(\mathrm{mm})$

L: Tohuma ait uzunluk değeri (mm)

D: Tohuma ait ortalama aritmetik çap (mm)

Küresellik:

$\Phi: D o / L$

$\Phi$ : Tohumun küresellik değeri

Do : Tohum ortalama geometrik çap (mm)

$\mathrm{L}$ : Tohum uzunluğu (mm)

Tablo 2. Kenevir tohumlarına ait bazı fiziksel özellikler

\begin{tabular}{|c|c|c|c|c|c|c|c|c|}
\hline \multirow{2}{*}{ Tohum özellikleri } & \multicolumn{4}{|c|}{ 1. y1l } & \multicolumn{4}{|c|}{ 2. y1l } \\
\hline & Min. & Ort. & Mak. & Stdv. & Min. & Ort. & Mak. & Stdv. \\
\hline Uzunluk (mm) & 6.929 & 8.620 & 10.339 & 0.720 & 6.031 & 7.690 & 8.935 & 0.688 \\
\hline Genişlik (mm) & 5.226 & 6.408 & 7.725 & 0.548 & 4.970 & 6.110 & 6.950 & 0.478 \\
\hline Yüzey alan $\left(\mathrm{mm}^{2}\right)$ & 31.580 & 43.703 & 59.530 & 6.523 & 24.550 & 37.635 & 48.722 & 5.288 \\
\hline Ortalama Aritmetik Çap (mm) & 6.394 & 7.514 & 9.032 & 0.591 & 5.514 & 6.900 & 7.853 & 0.518 \\
\hline Ortalama Geometrik Çap (mm) & 94.412 & 165.262 & 281.142 & 39.772 & 61.123 & 124.203 & 180.682 & 27.898 \\
\hline Küresellik & 13.626 & 18.937 & 27.192 & 2.990 & 10.135 & 15.959 & 20.554 & 2.337 \\
\hline Bin dane ăğırlı̆̆g (g) & 16.100 & 17.075 & 18.900 & 1.276 & 13.300 & 13.775 & 14.400 & 0.457 \\
\hline
\end{tabular}




\section{Araştırma Sonuçları ve Tartışma}

\subsection{Kenevir tohumlarına ait bazı fiziksel özellikler}

Kenevir bitkisine (Cannabis sativa L.) ait tohumların özelliklerine dair elde edilen sonuçlar temel istatistik parametrelere göre değerlendirdiğimizde; tohumların ölçülerinin ilk seneye göre ikinci senede arttı̆̆ belirlenmiştir (Tablo 2). Ayrıca, tohumların kısa ve oval bir tohum yapısına sahip olduğu belirlenmiştir. Gönen (2009)'in yapmış olduğu çalışmada kenevir tohumlarının oblong-eliptik yaklaşık 3-6 mm boyutlarında (9 farklı yöreden gelen kenevir tohumlarının uzunluk ve genişlik ölçülerini $2-5.5 \mathrm{~mm}$ arasında değiştiğini) olduğunu belirtirken; bu araştırmada incelenen kenevir tohumlarının oval bir yapıya sahip olmaları paralellik göstermiş ancak tohum ebatları farklı ölçülmüştür. Benzer durum, Gün (2019)'ün yapmış olduğu çalışmada kenevir tohumlarının boyutlarının $4 \mathrm{~mm}$ uzunluk ve $3 \mathrm{~mm}$ genişlik olarak gözlenmiş; İncekara (1979) ise, 4-6 mm uzunluk ve 3-3.5 mm genişliğe sahip olduğunu belirtmişlerdir ancak bu çalışmada incelenen tohum boyutlarının yaklaşı 2 kat daha yüksek değerlere sahip olduğu belirlenmiştir. $\mathrm{Bu}$ durum çalışmada incelenen Narlı popülasyonunun Ege Bölgesi iklim ve çevre koşullarına adaptasyonun iyi olduğunu ve bu durumun verime doğrudan olumlu yönde etki edeceğini ortaya koymaktadır.

İncekara (1979), Gönen (2009) ve Gün (2019) yaptıkları çalışmalarında kenevir tohumlarının ağırlıklarının Türkiye'de $12-30 \mathrm{~g}$, diğer ülkelerde ise 14-22 $\mathrm{g}$ arasında bin dane ağırlı̆̆ına sahip olduğnu belirlemişlerdir. Bu çalışmada, tohumların bin dane ağırlıkları 1. yıl için ortalama $17.075 \mathrm{~g}, 2$. y1l için ortalama $13.775 \mathrm{~g}$ olarak tartılmış ve önceki yapılan araştırmalar ile örtüştüğü saptanmıştır.

\section{Sonuc}

$\mathrm{Bu}$ çalışmada, iki yıl boyunca gerçekleştirilen bitkisel üretim sonunda elde edilen kenevir (Cannabis sativa L.) bitkisine ait tohumlar incelenmiştir. Rastgele olacak şekilde örneklenen bu tohumların bazı fiziksel özellikleri belirlenmiştir. Elde edilen veriler yıl bazında temel istatistik parametreler göz önüne alınarak değerlendirilmiştir. Buna göre; ikinci yılda elde edilen tohumların ilk yıla oranla çok daha yüksek değerlere sahip olduğu belirlenmiştir. $\mathrm{Bu}$ durum, çalışmada bitkisel materyal olarak kullanılmış olan Narlı popülasyonunun Ege bölgesi iklim, çevre ve toprak özelliklerinden maksimum fayda sağladığını ortaya koymuştur. İleride yapılacak olan islah çalışmalarında çevreye olan adaptasyon yeteneği göz önüne alınarak, endüstriyel anlamda kenevir üretiminin mekanizasyon yardımı ile gerçekleştirilmesini olanaklı kılmaktadır.

\section{Kaynakça}

Alayunt, F.N. (2000). Biyolojik Malzeme Bilgisi, Ege Üniversitesi Ziraat Fakültesi Tarım Makineleri Bölümü Ders Kitabı, Ege Üniv. Ziraat Fak. Yayınları No: 541.

Anderson, L.C. (1980). Leaf variation among Cannabis species from a controlled garden. Botanical Museum Leaflets. Harward University. 28(1):61-69.

Antonisamy, P., Duraipandiyan, V., Ignacimuthu, S. \& Kim, J.H. (2015). Anti-diarrhoeal activity of friedelin isolated from Azima tetracantha lam. in wistar rats. South Indian Journal of Biological Sciences. 1(1):34-37.

Aswar, U.M., Ehaskaran, S., Mohan, V. \& Bodhankar, S.L. (2010). Estrogenic activity of friedelim rich fraction (INDHE) separated from Cissus quadrangularis and its effect on female sexual function. Pharmacognosy Research. 2(3):138.
Aydemir, T. (2017). Farklı tarımsal artıkların kullanılarak hazırlanan karşım peletlerinde kenevir sapı kullanımının pelet kalite özellikleri üzerine etkisi. Tekirdağ Namık Kemal Üniversitesi, Fen Bilimleri Enstitüsü Biyosistem Mühendisliği ABD, Yüksek Lisans Tezi, Tekirdağ.

Aytaç, S., Ayan, A.K. \& Arslanoğlu, Ş.F. (2017). Keten-KendirIsırgan. Endüstriyel Tip Kenevir Yetiştiriciliği Karadeniz Lif Bitkileri Çalıştayı (5-6 Mayıs). S.27-35, Samsun.

Başer, U. \& Bozoğlu, M. (2020). Türkiye'nin kenevir politikası ve piyasasına bir bakış. TEAD. 6(2):127-135.

Dumanoğlu, Z. \& Çakmak, B. (2019). Tohum Uygulamalarının Soğan (Allium cepa L.) Tohumunun Bazı Fiziksel ve Mekanik Özelliklerine Etkisi, Bursa Uludağ Üniv. Ziraat Fakültesi Dergisi, 33(1), ISSN: 1301-3165.

Dumanoğlu, Z. \& Geren, H. (2020). An Investigation on Determination of Seed Characteristics of Some Gluten-Free Crops (Amarantus mantegazzianus, Chenopodium quinoa Willd., Eragrostis $\quad$ tef [Zucc] Trotter, Salvia hispanica L.). Turkish Journal of Agriculture-Food Science and Technology. 8(8), 1650-1655.

Dumanoğlu, Z. \& Mokhtarzadeh, S. (2020). Türkiye'de Kültürü Yapılan Salvia Türlerine (Salvia hispanica L., Salvia tomentosa Mill. ve Salvia verticillata L.) Ait Tohumların Bazı Fiziksel Özellikleri, Türk Tarım ve Doğa Bilimleri Dergisi 7(3): 596-602.

Dumanoğlu, Z., Çaçan, E. \& Kökten K. (2021). Korunga (Onobrychis viciifolia Scop.) genotiplerine ait tohumların fiziksel özelliklerinin belirlenmesi. Journal of Anatolian Environmental and Animal Sciences. 6(1):18-24.

Er, C. \& Yıldız, M. (2014). Keyf Bitkileri. Ankara Üniversitesi Ziraat Fakültesi Yayınları. Yayın No: 1616, Ankara.

FAO (2019). Food and Agriculture Organizastion of HempCultivation and Production Statistical Data. (FAOSTAT).(www.fao.org/faostat/)

Garia-Tejero, I.F., Durán Zuazo V.H., Pẻrez-Álvarez, R., Herández, A., Casano S., Morón, M. \& Muriel, J.L. (2014). Impact of plant density and irrigation on yield of hemp (Cannabis sativa L.) in a Mediterranean semi-arid environment. Journal of Agriculture Science Technology. 16:887-895.

Gizlenci, Ş., Acar, M., Yiğer, Ç. \& Aytaç, S. (2019). Kenevir tarımı. TC. Tarım ve Orman Bakanlığ 1 Tarımsal Araştırmalar ve Politikalar Genel Müdürlüğü Karadeniz Tarımsal Araştırma Enstitüsü Müdürlüğü, Samsun.

Göre, M \& Kurt, O. (2021). Bitkisel üretimde yeni bir trend: Kenevir. International Journal of Life Sciences and Biotechnology. 4(1):138-157.

Gönen, S. (2009). Cannabis sativa L. bitkisinin morfolojisi ve anatomisi üzerine bir araştırma. Ege Üniversitesi Fen Bilimleri Enstitüsü Biyoloji ABD. Yüksek Lisans Tezi, İzmir.

Gün, M. (2019). Türkiye kenevir (Cannabis sativa L.) genotiplerinin morfolojik karakterizasyonu. Samsun Ondokuz Mayıs Üniversitesi Fen Bilimleri Enstitüsü Tarla Bitkileri ABD. Yüksek Lisans Tezi, Samsun.

İbiş, D.S. (2020). Samsun ili kenevir işletmelerinde mekanizasyon kullanım durumu ve kenevir tarımı swot analizi, Samsun Ondokuz Mayıs Üniversitesi Fen Bilimleri Enstitüsü Tarım Makinaları ve Teknolojileri ABD, Yüksek Lisans tezi, Samsun

International Rules for Seed Testing (ISTA). (2007). International Rules for Seed Testing Book.

İncekara, F. (1979). Endüstri Bitkileri ve Islahı. Ege Üniversitesi 
Ziraat Fakültesi Yayınları, Yayın No: 65, İzmir.

Kara, M. (2012). Biyolojik Ürünlerin Fiziksel Özellikleri, Atatürk Üniv. Ziraat Fakültesi Yayınları No: 242.

Mathieu, J.P. (1980). Chanvre. Techniques Agricoles. 5:1-10.

Mohsenin, N.N. (1970). Physical Properties of Plant and Animal Materials. Gordon and Breach Science Publishers.

Oomah, B.D., Busson, M., Godfrey, D.V. \& Drover, J.C.G. (2002). Characteristics of hemp (Cannabis sativa L.) seed oil. Food Chem. 76:33-43.

Pounds, N.J.G. (2010). An Historical Geography of Europe. Cambridge University Press.

TÜIKK. (2020). Türkiye İstatistik Kurumu, Bitkisel Üretim İstatistikleri. (https://biruni.tuik.gov.tr/medas/)

Schultes, R.E., Klein, W.M., Plowman, T. \& Lockwood, T.E. (1974). Cannabis: An example of taxonomic neglect. Botanical Museum Leaflets. Harward University. 23(9):337367.

Vavilov, N.I. (2009). Orijin and Geograph of Cultvated Plants. Cambridge University Press. P:22-135.

Yağcıŏlu, A. (2015). Ürün İşleme, Ege Üniversitesi Yayınları Ziraat Fakültesi Yayın No: 517, Genişletilmiş 2. Baskı.

Yaman, C. (2020). Cannabis sativa L. (Kenevir)'de in vitro mikro çoğaltım. Sürdürülebilir Mühendislik Uygulamaları ve Teknolojik Gelişmeler Dergisi. 3(3):54-62.

Yıldırım, S. \& Koca Çalışkan U. (2020). Kenevir ve Sağlık Alanında Kullanımı. Ankara Ecz. Fak.Derg. 44(1):112-136. 